\title{
Desempenho, fibras musculares e carne de bovinos jovens de três grupos genéticos
}

\author{
Mário De Beni Arrigoni ${ }^{(1)}$, Armando Alves Júnior(1), Paulo Marcelo Amorim Dias( ${ }^{(1)}$, Cyntia Ludovico Martins ${ }^{(1)}$, \\ Rafael da Costa Cervieri(1), Antonio Carlos Silveira(1), Henrique Nunes de Oliveira ${ }^{(1)}$ e Luis Artur Loyola Chardulo(2)
}

(1)Universidade Estadual Paulista (Unesp), Faculdade de Medicina Veterinária e Zootecnia, Dep. de Melhoramento e Nutrição Animal, Caixa Postal 560, CEP 18618-000 Botucatu, SP. E-mail: arrigoni@fca.unesp.br,cludovico@fca.unesp.br, cervieri@bigfoot.com, acsilveira@fca.unesp.br, hnunes@fca.unesp.br, secdmna@fca.unesp.br (2)Unesp, Instituto de Biociências, Dep. de Química e Bioquímica. E-mail: lachard@ibb.unesp.br

Resumo - O objetivo deste trabalho foi avaliar as características de desempenho, carcaça, qualidade de carne e das fibras musculares esqueléticas de bovinos jovens de três grupos genéticos, Angus x Nelore, Canchim x Nelore e Simental x Nelore. Noventa bovinos inteiros mestiços jovens, com idade média de oito meses, sendo 30 de cada grupo genético, foram distribuídos em delineamento experimental inteiramente casualizado, com três tratamentos (grupos genéticos) e seis repetições. Nas análises das fibras musculares, foram utilizados seis animais por tratamento e na avaliação de desempenho e características de carcaça, foram utilizados todos os animais. Em relação a ganho de peso diário, rendimentos de carcaça e cortes cárneos, área do músculo longissimus dorsi e proteínas e lipídeos totais na carne, não houve diferença entre os grupos genéticos, porém os mestiços Angus apresentaram maior espessura de gordura subcutânea. A maciez da carne não variou entre os grupos genéticos e entre os períodos de 7 e 14 dias de maturação. A semelhança da maciez da carne de 7 e 14 dias permite que o tempo de maturação das carnes seja reduzido, quando se utiliza animais jovens.

Termos para indexação: confinamento, atributos de qualidade.

\section{Performance, muscle fibers and meat traits of young bulls of three genetic groups}

\begin{abstract}
The performance, carcass traits and quality of meat and muscle fibers of young bulls of three genetic groups, Angus x Nelore, Canchim x Nelore and Simmental x Nelore, were analysed. Ninety crossbred young bulls, averaging eight months old, being 30 of each genetic group, were allotted in a completely randomized design, with three treatments (genetic groups) and six replicates. Six animals per treatment were used for the analysis of muscular fibers, while for the evaluation of performance and carcass traits, all animals were used. Average daily gain, dressing percentage, primal cuts yield, rib eye area and total meat protein and fat did not differ among treatments. Angus crossbreed showed greater fat thickness than the other groups. Meat shear force values did not differ among genetic groups and between 7 and 14 days of maturation or aging time. Due to the similarity of the shear force values between 7 and 14 days of maturation, it is possible to reduce meat aging time when young bulls are used.
\end{abstract}

Index terms: feedlot, meat quality.

\section{Introdução}

Os consumidores consideram a maciez como um dos mais importantes componentes da qualidade da carne (Cundiff et al., 1993). Entre os maiores problemas da indústria de carne bovina, no Brasil e no mundo, encontra-se a falta de uniformidade em idade de abate dos animais, cobertura de gordura e marmorização da carne, fatores que possuem grande influência na maciez e palatabilidade do produto. Desta maneira, a variação de qualidade de carne bovina é atribuída à falta de padronização dos sistemas de produção, à genética do rebanho e à inabilidade em identificar as carcaças que produzem maior quantidade e melhor qualidade de carne (Shackelford et al., 1991).

A padronização dos sistemas de produção de carne é capaz de garantir um produto de qualidade específica, que atenda às exigências de mercado (Silveira, 2003). Em sistemas de produção intensiva de carne, a obtenção da máxima eficiência biológica aliada à rápida deposição do tecido muscular esquelético, representam as variáveis capazes de determinar o sucesso na adoção de tecnologia (Williams et al., 1995c; Silveira, 2003). Neste sentido, a delimitação da quantidade de carne 
produzida, associada à adequada terminação da carcaça, são fundamentais na determinação da eficiência biológica de animais de diferentes tamanhos à maturidade e taxas de crescimento, em sistemas intensivos de produção de carne.

Os programas de cruzamentos industriais e a importação de raças geneticamente superiores têm aumentado a cada ano, visando à produção de novilhos precoces (Silveira, 2003). Com a introdução destes programas, iniciou-se uma série de estudos visando obter produtos de melhor qualidade de carcaça e de carne. Entre estas qualidades desejáveis destacam-se o rendimento de cortes cárneos, porcentagem de gordura (subcutânea e intramuscular) na carcaça e maciez (Boleman et al., 1998). Desta maneira, várias pesquisas surgiram no intuito de se estudar as possíveis relações do tamanho à maturidade com as características de carcaça e de qualidade de carne.

Este trabalho teve por objetivo avaliar as características de desempenho, carcaça e qualidade da carne e das fibras musculares esqueléticas de bovinos jovens de três grupos genéticos.

\section{Material e Métodos}

O estudo foi desenvolvido no confinamento experimental do Dep. de Melhoramento e Nutrição Animal da Faculdade de Medicina Veterinária e Zootecnia (FMVZ) da Unesp, Campus de Botucatu, SP.

Noventa bovinos inteiros mestiços jovens, com idade média de oito meses, sendo 30 de cada um dos grupos genéticos: Angus x Nelore, Canchim x Nelore e Simental $\mathrm{x}$ Nelore, foram distribuídos em um delineamento experimental inteiramente casualizado, com três tratamentos (grupos genéticos) e seis repetições. Para a avaliação de desempenho e caraterísticas de carcaça, foram utilizados todos os animais $(30 \times 3)$.

O período de confinamento foi de 168 dias para atingir o peso de abate. Durante o confinamento, os animais receberam dieta em função da idade e da fase de crescimento, segundo formulação avaliada pelo National Research Council (1996). O consumo de alimentos foi ajustado com base na coleta das sobras do cocho, feita a cada três dias da semana. A dieta base experimental dos animais está apresentada na Tabela 1. A cada avaliação calculou-se o peso médio dos lotes e assim foram feitos os ajustes de consumo de matéria seca.

Os animais foram pesados em jejum de 16 horas a cada 28 dias e abatidos em frigorífico comercial, Len- çóis Paulista, SP, quando atingiram idade, peso e espessura de gordura subcutânea avaliada por ultra-som.

$\mathrm{Na}$ análise de ultra-som, foram utilizados todos os animais do ensaio $(\mathrm{n}=90)$. As avaliações da área do músculo longissimus dorsi (AOL) e espessura de gordura subcutânea (EGS) dos animais foram realizadas a partir de imagens obtidas entre a $12^{\text {a }}$ e a 13 a costelas, conforme técnica descrita por Perkins et al. (1992). Utilizou-se aparelho de ultra-som veterinário PIE MEDICAL - Scanner 200, com uma sonda linear de $17,2 \mathrm{~cm}$ e $3,5 \mathrm{MHz}$ (Sector Curved Array Scanner, modelo 51B04UM02).

As análises de maciez foram executadas no Laboratório de Qualidade de Carnes do Dep. de Melhoramento e Nutrição Animal FMVZ, da Unesp, Botucatu, SP. As amostras foram obtidas entre a 11 a 13 a costelas das meia-carcaças esquerdas dos animais amostrados. Foi adotado o procedimento padronizado e proposto por Wheeler et al. (1995), em que as referidas amostras são congeladas e embaladas em saco de plástico adequado, após resfriamento de 24 horas. As análises de textura foram realizadas nas amostras resfriadas por 24 horas, e nas amostras maturadas por 14 dias. No início das análises, as amostras foram descongeladas sob refrigeração $\left(5^{\circ} \mathrm{C}\right)$ durante 24 horas e, quando a temperatura interna atingiu de 5 a $6^{\circ} \mathrm{C}$, foram colocadas em forno elétrico para serem assadas. No procedimento de cozimento, foi introduzido no centro geométrico de cada amostra um termoacoplador ligado em termômetro digital, com o objetivo de monitorar a temperatura interna até o limite de $71^{\circ} \mathrm{C}$, quando as amostras foram retira-

Tabela 1. Quantidade e porcentual de alimento com base na matéria seca (MS), energia líquida de manutenção (Elm), energia líquida para ganho (Elg) e proteína bruta (PB) da dieta experimental de bovinos de corte ${ }^{(1)}$.

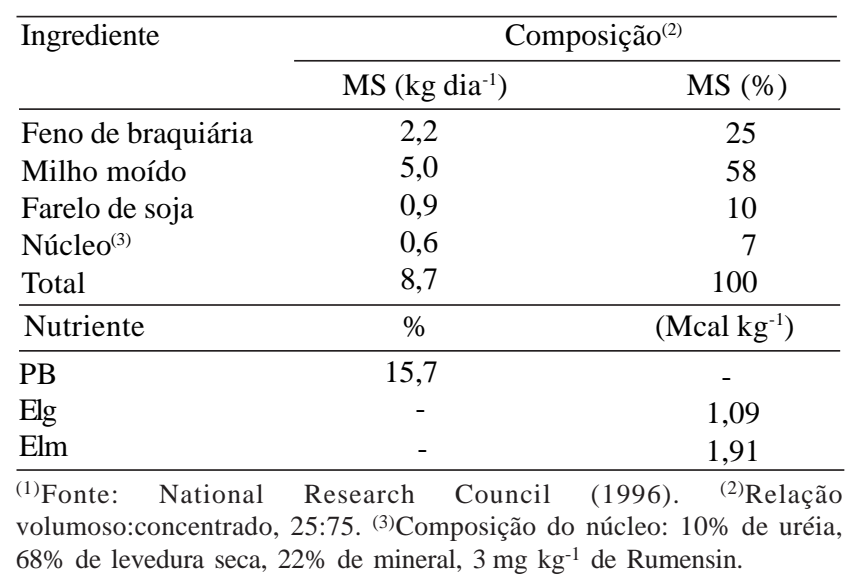


das do forno e resfriadas em ambiente livre até atingirem temperatura interna de $24 \mathrm{a} 25^{\circ} \mathrm{C}$. A seguir, as amostras foram colocadas em resfriamento $\left(5\right.$ a $\left.6^{\circ} \mathrm{C}\right)$ durante 24 horas, quando se iniciou a retirada de oito cilindros do seu interior. Para a determinação da força de cisalhamento, utilizou-se o aparelho mecânico WarnerBratzler Shear Force, com capacidade de $25 \mathrm{~kg}$ e velocidade do seccionador de $20 \mathrm{~cm} \mathrm{~min}^{-1}$. Utilizou-se a média das oito medidas por amostra para obter maior precisão nos resultados.

As análises químicas da carne foram realizadas no Laboratório de Química e Bioquímica do Instituto de Biociências da Unesp, Botucatu, SP, e as perdas por evaporação, gotejamento e totais das amostras foram executadas no Laboratório de Qualidade de Carnes do Dep. de Melhoramento e Nutrição Animal da FMVZ.

A porcentagem de gordura na carne foi analisada nas amostras cozidas para a determinação da força de cisalhamento, e utilizou-se o protocolo proposto por Bligh \& Dyer (1959), mais adequado para análise de amostras desta natureza, pois extrai todas as classes de lipídeos e não unicamente os compostos neutros, o que tem inegável valor nas avaliações dietéticas. Este método pode ser usado tanto com produtos absolutamente secos quanto com altos teores de água.

Foram pesados entre 3,0 a 3,5 g de amostras de carne moída, transferidas para erlenmeyer de $250 \mathrm{~mL}$ onde foram adicionados $10 \mathrm{~mL}$ de clorofórmio, $20 \mathrm{~mL}$ de metanol e $8 \mathrm{~mL}$ de água destilada e submetidos à agitação horizontal por 30 minutos. Em seguida adicionaramse $10 \mathrm{~mL}$ de clorofórmio e $10 \mathrm{~mL}$ de solução aquosa de sulfato de sódio $1,5 \%$, aos tubos, que foram agitados vigorosamente por dois minutos e centrifugados a $1000 \mathrm{~g}$ por dois minutos. Descartou-se a camada sobrenadante e filtrou-se rapidamente a inferior (para evitar evaporação do clorofórmio) em tubo de $30 \mathrm{~mL}$. A solução foi filtrada novamente e $5 \mathrm{~mL}$ do filtrado foram transferidos para um béquer de $50 \mathrm{~mL}$, previamente dessecado e pesado. $\mathrm{O}$ béquer foi colocado em estufa a $110^{\circ} \mathrm{C}$ até evaporar o solvente (15 a 20 minutos), posteriormente resfriado em dessecador $(\mathrm{O} / \mathrm{N})$ e pesado. As diferenças de peso do béquer, acrescidas ao peso da amostra, em relação ao peso do béquer ao final do procedimento, permitiram determinar as quantidades porcentuais de lipídeos na amostra. Os resultados representam os valores quantitativos das características de marmorização da carne.

As perdas por evaporação, gotejamento e totais foram obtidas pela pesagem das bandejas de cozimento, com e sem as amostras. As pesagens foram feitas antes e após o cozimento das amostras e a relação porcentual de perda de peso das bandejas com as amostras refere-se às perdas por evaporação. $\mathrm{O}$ acréscimo de peso das bandejas após o cozimento e sem as amostras representou as perdas por gotejamento que, acrescidas às perdas por evaporação, resultaram nas perdas totais de cozimento.

No estudo do diâmetro das fibras musculares esqueléticas do músculo semitendinosus (região do corte cárneo do lagarto) foram utilizados seis animais de cada tratamento $(\mathrm{n}=18)$. As amostras foram colhidas aos 295 dias de idade, por biópsia e por ocasião do abate. A biópsia foi desenvolvida neste músculo por sua fácil identificação no animal in vivo e acesso facilitado por não apresentar excessiva cobertura de tecido adiposo, melhorando a padronização das amostras. As amostras foram colhidas após aplicação de anestésico local (xilocaína), sempre na mesma profundidade do músculo (Chayen, 1969). Após devidamente processadas e transformadas em fragmentos de aproximadamente $1,0 \mathrm{~cm}$ de comprimento e $0,5 \mathrm{~cm}$ de espessura, as amostras foram acondicionadas em Eppendorfs, identificadas, transportadas em nitrogênio líquido e posteriormente armazenadas em freezer a $80^{\circ} \mathrm{C}$ negativos. A identificação, contagem do número e diâmetro das fibras foi realizada no Laboratório de Histoenzimologia do Dep. de Morfologia do Instituto de Biociências, Unesp, Campus de Botucatu, SP.

As amostras de tecido foram transferidas para a câmara de um micrótomo criostato (Cryocut-1800Reichert-Jung), permanecendo a $-20^{\circ} \mathrm{C}$ por aproximadamente 45 minutos. Em seguida, foram fixadas perpendicularmente a um suporte metálico, utilizando-se resina Tissue tek - Optimal Critical Temperature Compound (OCT), e submetidas a uma série de cortes histológicos com $10 \mu \mathrm{m}$ de espessura, os quais foram colhidos em lâminas histológicas previamente aquecidas a $40^{\circ} \mathrm{C}$ (Eversole \& Standish, 1970).

Para verificar a orientação das fibras musculares e a integridade das amostras, a primeira série de cortes foi fixada com a solução formol-cálcio de Baker por 5 minutos, lavados em água corrente e corados pela técnica da Hematoxilina-Eosina (HE) descrita por Lillie (1954).

Uma segunda série de cortes foi utilizada para demonstração da atividade da nicotinamida adenina tetrazólio redutase (NADH-TR), utilizando-se a técnica modificada por Dubowitz \& Brooke (1973). Para demonstração da atividade ATPásica miofibrilar 
(m-ATPase), utilizou-se o método descrito por Dubowitz \& Brooke (1973).

A nomenclatura adotada para os diferentes tipos de fibras obedeceu aos critérios de Peter et al. (1972), que classificaram as fibras em SO (fibras de contração lenta, metabolismo oxidativo e coloração vermelha), FOG (contração rápida, metabolismo oxidativo-glicolítico e coloração intermediária) e FG (contração rápida, metabolismo glicolítico e coloração branca).

$\mathrm{Na}$ identificação dos tipos de fibras, as lâminas foram analisadas em vários campos microscópicos, percorrendo-se toda a lâmina para obtenção do maior número de dados, utilizando-se uma câmara Newbauer acoplada a um microscópio óptico com ocular de 12,5X e objetiva de 40X. Para o cálculo das frequiências, nas amostras analisadas até então, foram contadas 300 fibras por lâmina, correspondendo à observação de 16 campos de visualização.

Na determinação do diâmetro das fibras, utilizou-se o software Optimas 4.10, em um analisador de imagens de microscopia óptica (Videoplan-Zeiss, Contron Electronics) com objetiva de $12,5 \mathrm{X}$ e tubo de imagem de $0,8 \mathrm{~mm}$. O diâmetro foi determinado com base na menor seção transversal, perpendicular ao eixo principal de visualização das fibras.

\section{Resultados e Discussão}

As características de desempenho e carcaça dos animais não diferiram $(\mathrm{P}>0,05)$ em ganho de peso diário (GPD), rendimento de carcaça (RC), rendimento de traseiro (RT), área do músculo longissimus dorsi (AOL), lipídeos e proteínas totais na carne (Tabela 2). Esses resultados denotam a habilidade de um sistema intensivo de produção de carne em padronizar as características de desempenho e de carcaça de animais de diferentes grupos genéticos e com diferentes taxas de crescimento.

Observou-se maior peso vivo nos mestiços Simental ao final do confinamento $(\mathrm{P}<0,01)$, porém não observa- ram-se maiores ganhos de peso diários no período experimental $(\mathrm{P}>0,05)$ neste grupo (Tabela 2). Os resultados de GPD encontram-se em conformidade aos encontrados por Sherbeck et al. (1995) e Williams et al. (1995c). As diferenças de peso vivo dos mestiços Simental, da ordem de $33 \mathrm{~kg}$, quando comparadas aos mestiços Angus, e de $46 \mathrm{~kg}$ em relação aos mestiços Canchim, foram decorrentes do maior peso ao desmame, que reflete positivamente no sistema de produção superprecoce, denotando a importância do peso ao desmame como reflexo positivo na obtenção de maiores pesos ao abate.

Apesar de a conversão alimentar não ter sido avaliada, considera-se que, à medida que os animais avançam na idade e no peso corporal, este parâmetro piora acentuadamente. Portanto, animais explorados na fase préconfinamento com maiores pesos ao desmame são mais eficientes, com engorda mais econômica, como demonstrado em trabalhos com animais superprecoces de vários grupos genéticos, em que a conversão alimentar média do início até 90 dias de confinamento foi de 5:1 e nos últimos 60 dias passou para 6,5:1 (Silveira, 2003).

O maior peso de abate dos mestiços Simental não refletiu em maior rendimento de carcaça, entretanto, observou-se maior quantidade de gordura perirenal (GPr), um componente não pertencente à carcaça, podendo ser uma das explicações para este resultado (Tabela 2). Cundiff et al. (1993) e Koch et al. (1993), trabalhando com animais de diferentes grupos genéticos, avaliaram a eficiência biológica em produção de carcaça e concluíram haver muitas diferenças entre as raças estudadas, na qual a Simental destacou-se por maior acúmulo de gordura visceral e perirenal.

As diferenças de deposição de tecido adiposo (EGS e GPr) entre os grupos genéticos, quando submetidos a dietas com alta proporção de concentrado (até 80\%), revelaram que os mestiços Angus apresentaram maior EGS $(\mathrm{P}<0,01)$ sem terem depositado maior quantidade de GPr, ao contrário dos mestiços Simental (Tabela 2). Esta observação nos permitiu inferir que a individuali-

Tabela 2. Ganho de peso diário (GPD), peso inicial (PI), peso final (PF), peso de carcaça quente (PCQ), rendimento de carcaça (RC), rendimento de traseiro (RT), gordura visceral (GV), área de olho de lombo (AOL), espessura de gordura subcutânea (EGS) e teor de lipídeos (LIP) em bovinos jovens mestiços ${ }^{(1)}$.

\begin{tabular}{lcccccccccc}
\hline Grupo genético & GPD $(\mathrm{kg})$ & PI $(\mathrm{kg})$ & PF $(\mathrm{kg})$ & PCQ $(\mathrm{kg})$ & RC $(\%)$ & RT $(\mathrm{kg})$ & GV $(\mathrm{kg})$ & AOL $\left(\mathrm{cm}^{2}\right)$ & EGS $(\mathrm{mm})$ & LIP $(\%)$ \\
\hline Angus x Nelore & $1,53 \mathrm{a}$ & $305,90 \mathrm{~b}$ & $444,20 \mathrm{a}$ & $244,01 \mathrm{a}$ & $54,94 \mathrm{a}$ & $64,65 \mathrm{a}$ & $4,77 \mathrm{a}$ & $72,77 \mathrm{a}$ & $6,43 \mathrm{a}$ & $0,026 \mathrm{a}$ \\
Canchim x Nelore & $1,48 \mathrm{a}$ & $305,85 \mathrm{~b}$ & $431,15 \mathrm{a}$ & $240,68 \mathrm{a}$ & $55,82 \mathrm{a}$ & $62,48 \mathrm{a}$ & $4,61 \mathrm{a}$ & $71,58 \mathrm{a}$ & $3,81 \mathrm{~b}$ & $0,021 \mathrm{a}$ \\
Simental x Nelore & $1,43 \mathrm{a}$ & $368,85 \mathrm{a}$ & $477,37 \mathrm{~b}$ & $261,68 \mathrm{~b}$ & $54,78 \mathrm{a}$ & $61,79 \mathrm{a}$ & $5,71 \mathrm{~b}$ & $73,56 \mathrm{a}$ & $3,69 \mathrm{~b}$ & $0,019 \mathrm{a}$ \\
\hline
\end{tabular}

${ }^{(1)}$ Médias seguidas de letras diferentes nas colunas diferem entre si pelo teste de Tukey a $1 \%$ de probabilidade. 
dade dos grupos genéticos deve ser considerada num programa de alimentação, uma vez que as características de acabamento não necessariamente estão associadas a maior peso e rendimento de carcaça, traduzindose em tecidos que não serão computados, como o caso da gordura perirenal. Estes resultados também foram observados por Cundiff et al. (1993) e Owens et al. (1993), independentemente do peso dos animais avaliados.

Apesar das poucas variações nas características de carcaça em razão dos grupos genéticos, não foram observadas diferenças no rendimento de traseiro (RT) entre os animais estudados, demonstrando que esses grupos foram especializados para produção de carne (Tabela 2). May et al. (1992), estudando novilhos em fase de crescimento, de diferentes tamanhos à maturidade, observaram que havia pouca relação nos índices de rendimento de carcaça, cortes cárneos comerciais e ganho de peso diário com o peso de abate e o início de maturação da carcaça. Com relação à variável idade, Chardulo (2000) observou pesos e rendimentos de carcaça de bovinos mestiços Simental x Nelore abatidos entre 12 e 15 meses de idade, semelhantes aos encontrados neste estudo. Os mesmos autores observaram ainda pouca variação nas características de carcaça e composição química da carne dos diferentes grupos genéticos quando submetidos a este sistema intensivo de produção.

Independentemente dos grupos genéticos estudados, pode-se observar diferenças nos valores de força de cisalhamento entre os períodos de 24 horas de resfriamento e de 7 e 14 dias de maturação, sendo que não foi observada diferença entre os períodos de $7 \mathrm{e}$ 14 dias de maturação (Tabela 3). Segundo Shackelford et al. (1991) e Koohmaraie et al. (2003), animais com proporção de genes Bos indicus superiores a $25 \%$ devem ser submetidos a períodos mínimos de 14 dias de maturação. Entretanto, observou-se que, em virtude da pouca idade dos animais, sete dias de maturação foram suficientes para conferir uma carne com valores de força de cisalhamento menores que $5 \mathrm{kgf}$, podendo ser considerada uma carne macia.

A concentração de proteínas totais do tecido muscular esquelético não diferiu entre os mestiços Angus, Canchim e Simental, com valores médios de 20,94, 21,02 e $21,50 \%$, respectivamente, demonstrando a pouca variação desta característica química na carne bovina, como evidenciado em outros estudos (Cundiff et al., 1993; Owens et al., 1993; Chardulo, 2000).

A avaliação das fibras musculares esqueléticas foi conduzida para acompanhar o crescimento dos animais em razão da idade e as particularidades de desenvolvimento muscular dos grupos genéticos estudados. Pôdese observar diferenças no diâmetro das fibras SO, FOG e FG em relação à idade dos animais, e SO e FOG, em relação aos grupos genéticos (Tabela 4). Essas diferenças nas fases de confinamento confirmam que o estudo das fibras musculares é uma ferramenta que reflete as diferenças e variações no crescimento dos músculos, corroborando com Arrigoni et al. (1998), Moreira et al. (2000) e Vann et al. (2001), os quais trabalharam com bovinos de corte machos e fêmeas jovens, respectivamente.

Animais de tamanhos corporais diferentes, representados neste estudo por mestiços Angus, Canchim e Simental, com pequeno, médio e grande porte, respectivamente, seguiram um comportamento diferente de crescimento e deposição tecidual em relação ao peso vivo de abate, área e espessura de gordura do músculo longissimus dorsi e tamanho de fibra muscular

Tabela 3. Força de cisalhamento (FC), perdas por evaporação (PE), perdas por gotejamento (PG) e perdas totais (PT) em razão do grupo genético e período de maturação do músculo longissimus dorsi de bovinos jovens mestiços ${ }^{(1)}$.

\begin{tabular}{lcclll}
\hline Grupo genético & Maturação & FC $\left(\mathrm{kgf} \mathrm{cm}^{-2}\right)$ & PE $(\%)$ & PG $(\%)$ & PT $(\%)$ \\
\hline Angus x Nelore & 24 horas & $4,53 \mathrm{a}$ & $0,181 \mathrm{a}$ & $0,053 \mathrm{a}$ & $0,234 \mathrm{ab}$ \\
& 7 dias & $3,48 \mathrm{~b}$ & $0,171 \mathrm{a}$ & $0,025 \mathrm{ab}$ & $0,195 \mathrm{ab}$ \\
& 14 dias & $3,87 \mathrm{a}$ & $0,202 \mathrm{a}$ & $0,032 \mathrm{ab}$ & $0,234 \mathrm{ab}$ \\
\hline Canchim x Nelore & 24 horas & $4,17 \mathrm{a}$ & $0,214 \mathrm{a}$ & $0,025 \mathrm{ab}$ & $0,024 \mathrm{ab}$ \\
& 7 dias & $3,46 \mathrm{~b}$ & $0,157 \mathrm{a}$ & $0,031 \mathrm{ab}$ & $0,182 \mathrm{~b}$ \\
& 14 dias & $3,50 \mathrm{~b}$ & $0,207 \mathrm{a}$ & $0,026 \mathrm{ab}$ & $0,237 \mathrm{ab}$ \\
\hline Simental x Nelore & 24 horas & $4,69 \mathrm{a}$ & $0,192 \mathrm{a}$ & $0,218 \mathrm{ab}$ \\
& 7 dias & $3,65 \mathrm{~b}$ & $0,172 \mathrm{a}$ & $0,028 \mathrm{ab}$ & $0,200 \mathrm{ab}$ \\
& 14 dias & $3,17 \mathrm{~b}$ & $0,174 \mathrm{a}$ & $0,020 \mathrm{~b}$ & $0,194 \mathrm{ab}$ \\
\hline
\end{tabular}

${ }^{(1)}$ Médias seguidas de letras diferentes nas colunas diferem entre si pelo teste de Tukey a 1\% (FC e PE) e a 5\% (PG e PT) de probabilidade. 
Tabela 4. Diâmetro $\left(\mu \mathrm{m}^{2}\right)$ das fibras musculares esqueléticas oxidativa de contração lenta (SO), oxidativa glicolítica de contração rápida (FOG) e glicolítica de contração rápida (FG) de bovinos jovens mestiços de diferentes grupos genéticos e idades $^{(1)}$.

\begin{tabular}{llll}
\hline Grupo genético & \multicolumn{1}{c}{ SO } & FOG & FG \\
\hline Angus x Nelore & $34,38 \mathrm{a}$ & $52,09 \mathrm{a}$ & $41,59 \mathrm{a}$ \\
Canchim x Nelore & $36,89 \mathrm{ab}$ & $52,25 \mathrm{a}$ & $41,30 \mathrm{a}$ \\
Simental x Nelore & $39,49 \mathrm{~b}$ & $54,83 \mathrm{a}$ & $42,71 \mathrm{a}$ \\
\hline Idade (dias) & & & \\
295 & $32,02 \mathrm{a}$ & $48,51 \mathrm{a}$ & $37,02 \mathrm{a}$ \\
408 & $41,83 \mathrm{~b}$ & $57,62 \mathrm{~b}$ & $46,72 \mathrm{~b}$ \\
\hline
\end{tabular}

${ }^{(1)}$ Médias seguidas de letras diferentes nas colunas diferem entre si pelo teste de Tukey a $1 \%$ de probabilidade.

esquelética SO. Mestiços Angus tiveram menores pesos vivo de abate e AOL, e maior EGS. Estas informações denotam as diferenças deste grupo em relação aos demais quanto ao crescimento dos tecidos, evidenciando a sua precocidade em depositar tecido adiposo em local adequado às características desejáveis da carne bovina (Owens et al., 1993; Wheeler et al., 1993; Williams et al., 1995a; Chardulo, 2000).

A maioria dos trabalhos sobre o desempenho de bovinos tem no peso vivo e ganho de peso os principais indicativos de crescimento, porém, observou-se que não houve diferença significativa entre os ganhos de peso dos grupos genéticos, mas pôde-se constatar que o padrão de crescimento foi diferente, em termos de precocidade de deposição dos tecidos muscular e adiposo, quando utilizaram-se mais parâmetros de avaliação.

Trabalhos clássicos desenvolvidos por Owens et al., (1993) e Willians et al. (1995b), os quais monitoraram o crescimento por ultra-som e pelas características de carcaça de animais puros, como Angus, Charolês e Simental, constataram que o acabamento e a porcentagem de gordura na carcaça são diferentes em virtude do tamanho à maturidade. Os resultados encontrados demonstraram que, mesmo com a participação de $50 \%$ de genes de animais Bos indicus (Nelore), foi possível verificar o mesmo comportamento, acrescentado com o estudo das fibras musculares.

A utilização de cruzamentos industriais no Brasil tem aumentado significativamente nos últimos anos, de modo a aumentar a eficiência da pecuária de corte. Entretanto, a grande maioria dos pecuaristas não leva em consideração o grau de acabamento dos animais, abatendo novilhos com pouca camada de gordura subcutânea, conseguindo, assim, menores preços pelos animais nos frigoríficos.

Quando se trabalha com o sistema de produção superprecoce, que padroniza o produto carne trazendo o abate dos animais para próximo de um ano, conseguese alta qualidade do produto, beneficiando não só o consumidor mas também o pecuarista, que aumenta a taxa de abate de seu rebanho, e a indústria frigorífica, que pode diminuir pela metade o tempo de maturação das carnes, reduzindo custos e tornando o processo mais lucrativo.

Os resultados reforçam a teoria de que os bezerros a serem abatidos como superprecoces devem ser desmamados com o maior peso possível, acima de $240 \mathrm{~kg}$, e com 240 dias de idade. Quanto menos os bezerros ficarem no confinamento, etapa produtiva que mais onera o sistema, mais econômico se torna o processo.

\section{Conclusões}

1. Os animais mestiços Angus x Nelore têm maior espessura de gordura subcutânea e menor diâmetro de fibra muscular esquelética, denotando suas diferenças quanto às características de carcaça quando comparados aos outros grupos genéticos.

2. $\mathrm{O}$ abate dos animais até 15 meses de idade permite diminuir para sete dias o tempo de maturação da carne.

\section{Agradecimentos}

À Fundação de Amparo a Pesquisa do Estado de São Paulo (Fapesp), pela concessão de bolsa e financiamento por meio do Projeto Temático no 99/05195-5.

\section{Referências}

ARRIGONI, M.D.B.; VIEIRA, P. de F.; SILVEIRA, A.C.; FURLAN, L.R.; DAL PAI, V.; COSTA, C.; CHARDULO, L.A.L.; OLIVEIRA, H.N. de. Estudo dos efeitos da restrição alimentar nas características das fibras musculares de bovinos jovens confinados. Pesquisa Agropecuária Brasileira, v.33, p.1121-1127, 1998.

BLIGH, E.G.; DYER, W.J. A rapid method of total lipid extraction and purification. Canadian Journal of Biochemistry and Physiology, v.37, p.911-917, 1959.

BOLEMAN, S.L.; BOLEMAN, S.J.; MORGAN, W.W.; HALE, D.S.; GRIFFIN, D.B.; SAVELL, J.W.; AMES, R.P.; SMITH, M.T.; TATUM, J.D.; FIELD, T.G.; SMITH, G.C.; GARDNER, B.A.; MORGAN, J.B.; NORTHCUTT, S.L.; DOLEZAL, H.G.; GILL, D.R.; RAY, F.K. National beef quality audit - 1995: Survey of producer-related defects and carcass quality and quantity attributes. Journal of Animal Science, v.76, p.96-103, 1998. 
CHARDULO, L.A.L. Desempenho, níveis plasmáticos de hormônios, expressão e quantificação de proteínas musculares, características de carcaça e qualidade de carne de bovinos inteiros jovens de cinco diferentes grupos genéticos submetidos a confinamento. 2000. 101p. Tese (Doutorado) - Universidade Estadual Paulista Júlio de Mesquita Filho, Jaboticabal.

CHAYEN, J. A guide to practical histochemistry. London: Oliver Bould, 1969. 261p

CUNDIFF, L.V.; KOCH, R.M.; GREGORY, K.E.; CROUSE, J.D.; DIKEMAN, M.E. Characteristics of diverse breeds in cycle IV of the cattle germplasm evaluation. Beef Research Progress Report, v.71, p.57-60, 1993.

DUBOWITZ, V.; BROOKE, M.H. Muscle biopsy: a modern approach. London: Saunders, 1973. 220p.

EVERSOLE, L.S.; STANDISH, S.M. Histochemical demonstration of muscle fiber types. Journal of Histochemistry and Cytochemistry, v.18, p.591-593, 1970.

KOCH, R.M.; CROUSE, J.D.; DIKEMAN, M.E.; CUNDIFF, L.V.; GREGORY, K.E. Effect of marbling on variation and change in beef tenderness in Bos taurus and Bos indicus crosses. Beef Research Progress Report, v.71, p.63-68, 1993.

KOOHMARAIE, M.; WHEELER, T.L.; SHACKELFORD, S.D. Beef tenderness: Regulation and prediction. Disponível em: <http:/ /meats.marc.usda.gov/MRU_WWW/TENDREV/TENDREV.html> Acesso em: 4 ago. 2003.

LILLIE, R.D. Histopathologic technic and practical histochemistry. $2^{\text {nd }}$ ed. New York: Blakiston, 1954. 510p.

MAY, S.G.; MIES, W.J.; EDWARDS, J.W.; WILLIAMS, F.L.; WISE, J.W.; MORGAN, J.B.; SAVELL, J.W.; CROSS, H.R. Beef carcass composition of slaughter cattle differing in frame size, muscle score, and external fatness. Journal of Animal Science, v.70, p.24312445, 1992.

MOREIRA, P.S.A.; SILVEIRA, A.C.; ARRIGONI, M.D.B.; COSTA, C.; CHARDULO, L.A.L.; FURLAN, L.R.; DAL PAI, V. Efeito da somatotropina na hipertrofia das fibras musculares esqueléticas e precocidade reprodutiva de novilhas Nelore. Pesquisa Agropecuária Brasileira, v.35, p.1853-1860, 2000.

NATIONAL RESEARCH COUNCIL (Washington, Estados Unidos). National Science Education Standards. Washington, DC: National Academies Press, 1996. Disponível em: <http:// nap.edu/catalog/4962.html> Acesso em: 4 de ago. 2003.

OWENS, F.N.; DUBESKI, P.; HANSON, C.F. Factors that alter the growth and development of ruminants. Journal of Animal Science, v.71, p.3138-3150, 1993.

PERKINS, T.L.; GREEN, R.D.; MILLER, M.F. Evaluation of alternative ultrasound measurement sites as estimators of yield grade factors in beef cattle. Proceedings, Western Section, American Society of Animal Science, v.43, p.294-297, 1992.

PETER, J.B.; BARNARD, R.J.; EDGERTON, V.R.; GILLESPIE, C.A.; STEMPEL, K.E. Metabolic profiles of three types of fibers of skeletal muscles in guinea pig and rabbits. Biochemistry, v.11, p.2627-2633, 1972.

SHACKELFORD, S.D.; KOOHMARAIE, M.; MILLER, M.F.; CROUSE, J.D.; REAGAN, J.O. An evaluation of tenderness of the longissimus muscle of Angus by Hereford versus Brahman crossbred heifers. Journal of Animal Science, v.69, p.171-177, 1991.

SHERBECK, J.A.; TATUM, J.D.; FIELD, T.G.; MORGAN, J.B.; SMITH, G.C. Feedlot performance, carcass traits, and palatability traits of Hereford and Hereford X Brahman steers. Journal of Animal Science, v.73, p.3613-3620, 1995.

SILVEIRA, A.C. Novilho superprecoce: técnicas de nutrição e manejo. In: SIMPÓSIO GOIANO SOBRE MANEJO E NUTRIÇÃO DE BOVINOS DE CORTE E LEITE, 5., 2003, Goiânia. Anais. Goiânia: Colégio Brasileiro de Nutrição Animal, 2003. p.153166.

VANN, R.C.; ALTHEN, T.G.; SOLOMON, M.B.; EASTRIDGE, J.S.; PAROCZAY, E.W.; VEENHUIZEN, J.J. Recombinant bovine somatotropin (rbST) increases size and proportion of fast-glycolytic muscle fibers in semitendinosus muscle of creep-fed steers. Journal of Animal Science, v.79, p.108-114, 2001.

WHEELER, T.L.; LARRY, V.C.; CUNDIFF, L.V.; KOCH, R.M. Effect of marbling degree on palatability and caloric content of beef. Beef Research Progress Report, v.71, p.133-134, 1993.

WHEELER, T.L.; KOOHMARAIE, M.; SHACKELFORD, S.D. Standardized Warner-Bratzler shear force procedures for meat tenderness measurement. Clay Center: Roman L. Hruska U. S. MARC. USDA, 1995. 7p.

WILLIAMS, C.B.; BENNETT, G.L.; KEELE, J.W. Simulated influence of postweaning production system on performance of different biological types of cattle: I. Estimation of model parameters. Journal of Animal Science, v.73, p.665-673, 1995a.

WILLIAMS, C.B.; BENNETT, G.L.; KEELE, J.W. Simulated influence of postweaning production system on performance of different biological types of cattle: II. Carcass composition, retail product, and quality. Journal of Animal Science, v.73, p. 674$685,1995 b$.

WILLIAMS, C.B.; BENNETT, G.L.; KEELE, J.W. Simulated influence of postweaning production system on performance of different biological types of cattle: III. Biological efficiency. Journal of Animal Science, v.73, p.686-698, 1995c.

Recebido em 2 de março de 2004 e aprovado em 2 de junho de 2004

Pesq. agropec. bras., Brasília, v.39, n.10, p.1033-1039, out. 2004 